\title{
SUPPLY AND DEMAND SYSTEM UNTUK HASIL BUDIDAYA IKAN LAUT BERBASIS WEBSITE
}

\author{
Dedi Rahman Habibie $^{{ }^{*} \text {, Sandy Suwandana }}{ }^{1}$ \\ ${ }^{1}$ Program Studi Sistem Informasi, Sekolah Tinggi Manajemen Informatika dan Komputer GICI \\ Email: *dedi.habibi@gmail.com
}

\begin{abstract}
Information on the availability of marine fish culture seeds is very important for marine fish cultivators, because availability affects prices and the sustainability of ongoing operations that require a supply of marine fish. In addition, suppliers are required to be able to meet demand for supply and keep it in balance with market demand so that market prices remain stable. The most basic problem is that the order or request process carried out by marine fish cultivators is still placing orders directly at that location. In addition, the fish supply may not be sufficient. Of course, this will take a lot of time during the order or request process between marine fish cultivators and suppliers. Another problem with suppliers is that when they are ready to harvest the fish industry, they must also be able to provide it to all parties who need a supply of fish. The purpose of this research is to design and build a web-based supply and demand system for marine aquaculture products, which is expected to encourage the supply and demand process for marine aquaculture products. The method used to analyze needs / needs in this study is structured analysis to obtain design results based on user needs.
\end{abstract}

Keywords: information systems; results of marine fish farming; supply and demand system.

\begin{abstract}
Abstrak: Informasi tentang ketersediaan bibit budidaya ikan laut sangat penting bagi pelaku pembudidaya ikan laut, karena ketersediaan mempengaruhi harga dan keberlangsungan operasi yang sedang berlangsung yang membutuhkan pasokan ikan laut. Selain itu, pemasok dituntut untuk dapat memenuhi permintaan penawaran dan menjaganya tetap seimbang dengan permintaan pasar agar harga pasar tetap stabil. Permasalahan yang paling mendasar adalah proses order atau request yang dilakukan oleh pembudidaya ikan laut masih melakukan order langsung ditempatkan di lokasi tersebut. Selain itu, pasokan ikan mungkin tidak mencukupi. Tentunya hal ini akan menyita banyak waktu saat proses pemesanan atau request antara pelaku pembudidaya ikan laut dan supplier. Masalah lain dengan pemasok adalah ketika mereka siap memanen industri ikan, mereka juga harus bisa menyediakannya kepada semua pihak yang membutuhkan pasokan ikan. Tujuan dari penelitian ini adalah merancang dan membangun sistem supply and demand produk budidaya ikan laut berbasis web, yang diharapkan dapat mendorong proses supply and demand produk budidaya ikan laut. Metode yang digunakan untuk menganalisis kebutuhan / kebutuhan dalam penelitian ini adalah analisis terstruktur untuk mendapatkan hasil perancangan berdasarkan kebutuhan pengguna.
\end{abstract}

Kata kunci: sistem informasi; supply and demand system; hasil budidaya ikan laut. 
DOI: https://doi.org/10.33330/jurteksi.v7i1.959

Available online at http://jurnal.stmikroyal.ac.id/index.php/jurteksi

\section{PENDAHULUAN}

Pemanfaatan teknologi informasi merupakan sesuatu yang harus dicapai hampir di semua aspek. Di bidang manajemen, seperti evaluasi kinerja dosen [1], pada bidang kedokteran seperti identifikasi awal penyakit limfoma[2] dan penyakit infertilitas[3], pada bidang pertanian seperti diagnosis hama dan penyakit bawang merah [4], pada bidang industri misalnya memprediksi jumlah produksi[5], pada bidang bisnis misalnya memberikan rekomendasi handphone terbaik kepada pelanggan[6], maupun pemerintahan. Dengan menggunakan teknologi informasi akan mendorong aktivitas dan kinerja agar lebih cepat dan mudah dalam memperoleh dan mengolah informasi. Memerlukan akses yang cepat terhadap kegiatan dan pengelolaan informasi agar kegiatan dan kinerja bisnis dapat berkembang lebih cepat sehingga mampu bersaing dalam skala nasional dan global.

Kota Batam berada dalam provinsi Kepulauan Riau yang terdiri dari beberapa pulau yakni pulau Batam, Rempang dan Galang serta pulau-pulau kecil lainnya yang dihubungkan oleh jembatan Barelang yang berada dalam kawasan selat Singapura dan selat Malaka yang memiliki banyak potensi dalam membudidayakan ikan laut dan tangkapan hasil laut karena sebuah kota yang memiliki daerah lautan yang luas. Informasi mengenai ketersediaan hasil budidaya ikan laut merupakan hal penting bagi pelaku bisnis terkait karena ketersediaan akan mempengaruhi harga dan keberlangsungan bisnis yang sedang dijalankan, salah satunya adalah pelaku bisnis usaha kuliner yang membutuhkan pasokan ikan laut. Selain itu pemasok juga diharuskan mampu memenuhi dan menyeimbangkan antara pasokan dengan kebutuhan pasar sehingga harga dipasaran dapat dijaga kestabilannya.

Penelitian mengenai supply and demand sudah dilakukan sebelumnya oleh peneliti terdahulu, diantaranya untuk lahan pertanian[7], sebagai penyedia tenaga kerja bidang bangunan[8], untuk analisa ketersediaan beton readymix[9], kredit perdagangan mikro, kecil dan usaha menengah [10], pembangunan Park And Ride Scheme di koridor timur kota bandung[11]. Pemanfaatan bidang sistem informasi pada pertumbuhan ekonomi sangat berpengaruh, pengaruh tersebut dapat dirasakan banyaknya penelitian sistem informasi di bidang ekonomi seperti: agribisnis e-commerce pemasaran buah pisang [12], pengadaan bahan baku[13], Permintaan Barang ATK Berbasis Web[14], pengadaan barang pada koperasi karyawan Aqua Group[15].

Permasalahan yang paling mendasar adalah proses order atau request yang dilakukan oleh pembudidaya ikan laut masih melakukan order langsung ditempatkan di lokasi tersebut. Selain itu, pasokan ikan mungkin tidak mencukupi. Tentunya hal ini akan menyita banyak waktu saat proses pemesanan atau request antara pelaku pembudidaya ikan laut dan supplier. Masalah lain dengan pemasok adalah ketika mereka siap memanen industri ikan, mereka juga harus bisa menyediakannya kepada semua pihak yang membutuhkan pasokan ikan. Tujuan dari penelitian ini adalah merancang dan membangun sistem supply and demand produk budidaya ikan laut berbasis web, yang diharapkan dapat mendorong proses supply and demand produk budidaya ikan laut. 


\section{METODE}

Tahapan yang dilalui dalam penelitian, pembangunan konsep, atau penyelesaian kasus, dituliskan pada bagian metodologi.

Pada penelitian ini, penelitian dilakukan di Balai Perikanan Budidaya Laut (BPBL) Batam dengan cara melakukan wawancara serta pengambilan data pada bagian informasi umum serta meninjau langsung lokasi pembudidayaan ikan laut. Jumlah responden yang dilibatkan pada penelitian ini sejumlah 10 responden yang melibatkan 3 Responden dari Balai Perikanan Budidaya Laut (BPBL) dan 43 Responden yang terdiri dari pembudidaya ikan laut yang berada di Tanjungpinang sebanyak 2 responden, Kep. Meranti sebanya 10 responden, Bintan 17 responden, Dumai 1 Responden, Bengkalis 1 responden, Karimun 2 responden dan Batam 10 responden.

Analisis yang dilakukan dalam pengembangan sistem pengolahan data narasumber adalah analisis terstruktur. Model analisis terstruktur adalah kegiatan membangun model. Model analisis harus mencapai tiga tujuan utama, yaitu mendeskripsikan kebutuhan pengguna (user), menetapkan dasar perancangan perangkat lunak (software), dan menentukan sekumpulan kebutuhan yang dapat diverifikasi sejak perangkat lunak dibangun. Untuk mencapai tujuan tersebut maka bentuk analisis terstruktur dapat diilustrasikan pada gambar 1. b [16]:

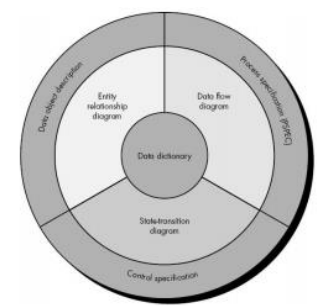

Gambar 1. Elemen Analisis Terstruktur
Analisis model ini juga disebut berorientasi proses. Analisis terstruktur sederhana secara konseptual. Analis menggambarkan serangkaian proses dalam bentuk diagram aliran data yang menggambarkan proses yang ada atau yang diusulkan serta masukan, keluaran, dan dokumentasinya. Dalam analisis terstruktur, tiga grafik berbeda dapat digunakan, yaitu: Entity Relation Diagram (ERD), Data Flow Diagram (DFD), dan State Transition Diagram (STD) [17].

\section{HASIL DAN PEMBAHASAN}

Setelah dilakukan proses model analisis terstruktur selanjutnya akan ditampilkan hasil implementasi sistem yang dibangun. Implementasi adalah untuk melengkapi implementasi desain. Hasil dari aplikasi ini merupakan sistem pengerjaan statics yang berperan dengan bagus. Implementasinya merupakan sebagai berikut:

1. Halaman Dashboard Customer Pada halaman dashboard Customer, akan ditampilkan fitur Data Permintaan, Data Stok Komoditas dan Tata Tertib. Untuk melihat info pada masing-masing fitur tersebut maka Customer harus mengklik menu info lebih lanjut.

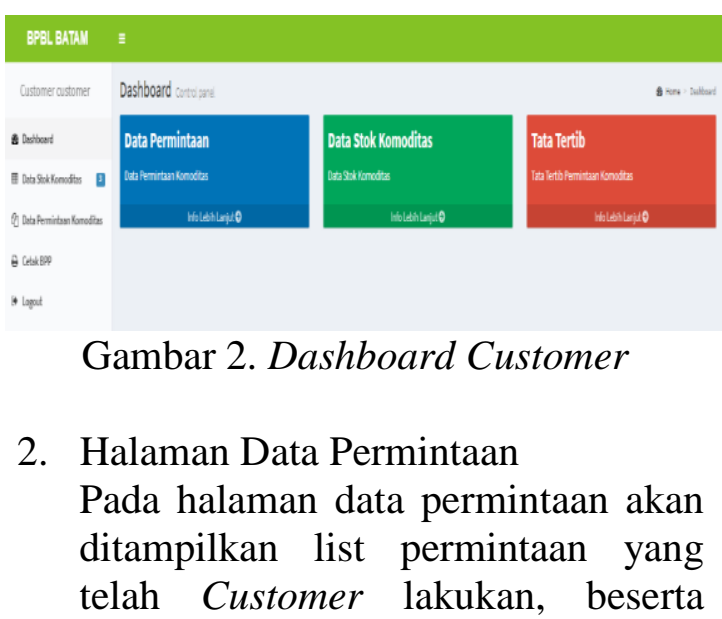


menu untuk menambah permintaan.

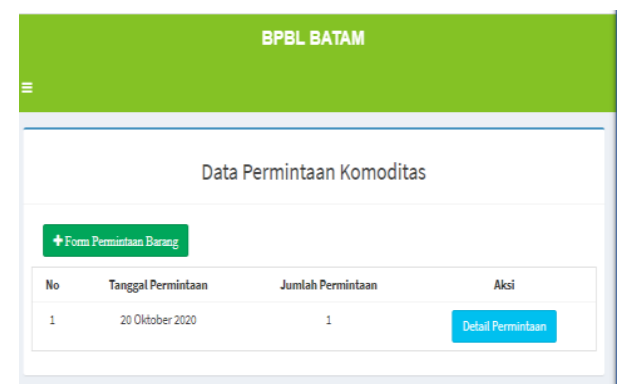

Gambar 3. Permintaan Customer

3. Form Permintaan Barang

Halaman form aplikasi proyek akan menampilkan field yang harus diisi pelanggan dengan jenis ikan yang dipesan yaitu ikan, kerapu dan kakap putih. Setelah memilih jenis ikan, sistem akan menampilkan stok yang tersedia, kemudian pelanggan akan memasukkan jumlah pesanan

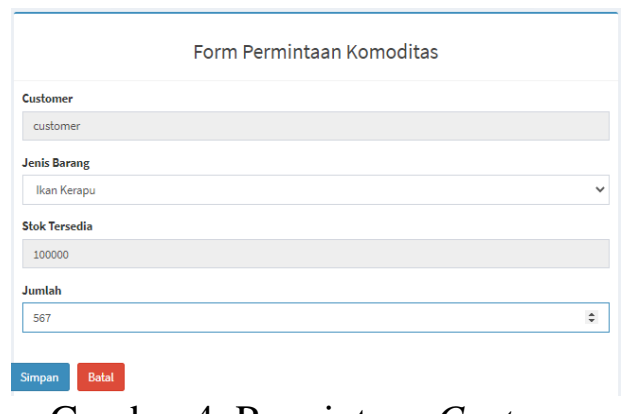

Gambar 4. Permintaan Customer

4. Halaman Data Permintaan

Jika pelanggan berhasil memasukkan data permintaan, halaman data permintaan akan diisi.

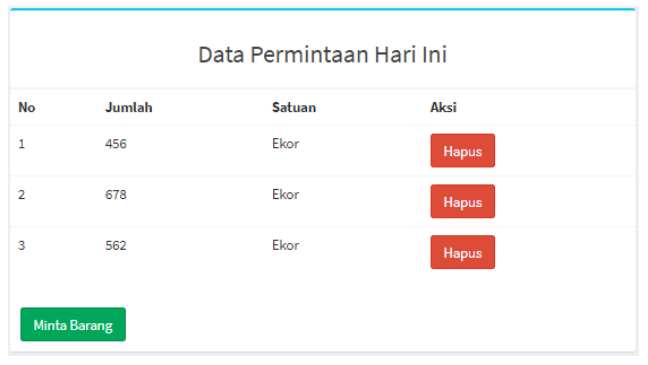

Gambar 5. Data Permintaan
5. Halaman Detail Data Permintaan Halaman data permintaan barang akan tampil ketika Customer mengklik tombol minta barang.

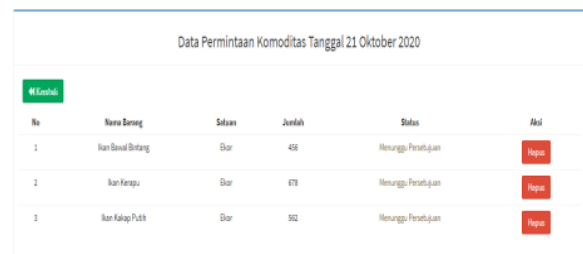

Gambar 6. Detail Data Permintaan

6. Costumer Melihat Stok Ikan

Pada halaman ini akan ditampilkan kepada Customer mengenai stok ikan bawal bintang yang tersedia.

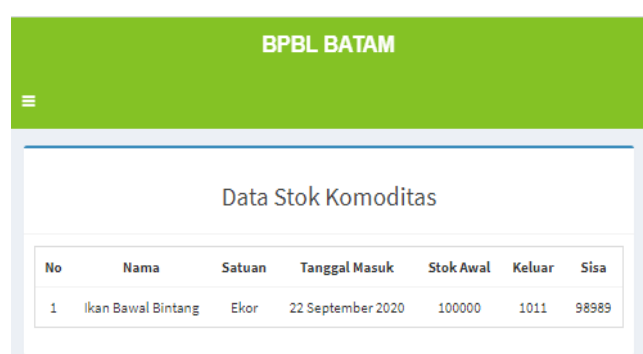

Gambar 7. Stok Ikan Bawal

7. Halaman Dashboard Admin Gudang Halaman dashboard manajemen gudang menampilkan data pengguna, meminta data dan menghentikan fungsi data. Untuk melihat informasi dari masing-masing fungsi, pengelola gudang harus mengklik menu more information.

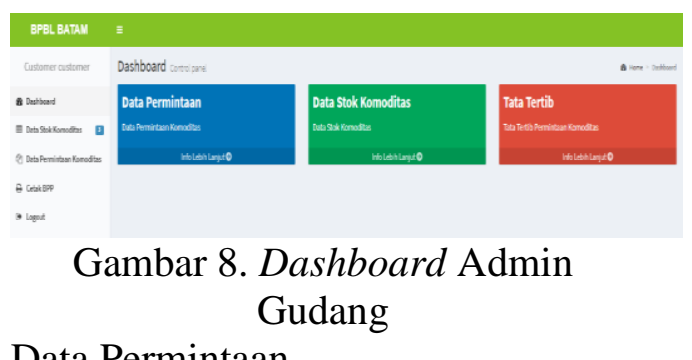

8. Data Permintaan

Pada halaman ini, admin dapat melihat data permintaan yang dilakukan oleh Customer. 


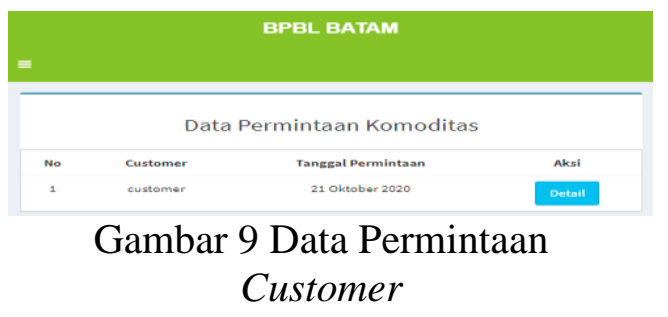

9. Data Detail Permintaan

Pada halaman ini, admin dapat melihat detail data permintaan yang dilakukan oleh Customer.

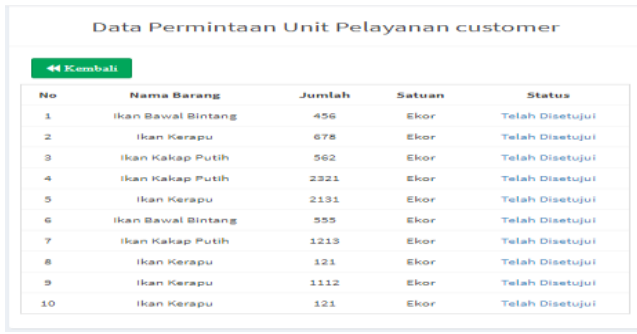

Gambar 10. Detail Data Permintaan Customer

10. Halaman Data Pengeluaran Komoditas

Pada halaman Data Pengeluaran Komoditas akan menampilkan Tanggal permintaan dan jumlah permintaan yang dilakukan oleh Customer

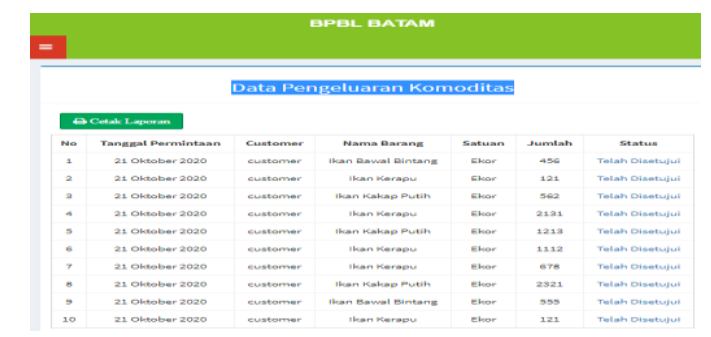

Gambar 11. Halaman Pengeluaran Komoditas

\section{SIMPULAN}

Berdasarkan keseluruhan proses analisis, perancangan dan implementasi, sistem supply and demand hasil budidaya ikan laut berbasis web (studi kasus: Balai Budidaya Perikanan Laut) dabangun sistem supply and demand dapat memudahkan BPBL Batam dalam menyediakan pasokan ikan. Memperkenalkan ikan di BPBL batam kepada pelanggan. Penawaran yang diberikan berupa Bawal Bintang, Kerapu dan Kakap Putih yang masing-masing memberikan informasi jumlah persediaan yang disediakan. Sistem supply dan design yang sudah builtin juga memudahkan pelanggan untuk melakukan request ke BPBL Batam tanpa harus mengunjungi BPBL Batam secara langsung. Manfaat lainnya, BPBL dapat lebih mudah mereview laporan ketersediaan sumber daya ikan, jumlah pesanan, laporan keluar ikan, dan mengelola data pengguna.

\section{DAFTAR PUSTAKA}

[1] D. Aldo, N. Putra, Z. Munir, P. Studi Sistem Informasi, and $\mathrm{S}$. Gici, "Sistem Pendukung Keputusan Penilaian Kinerja Dosen Dengan Menggunakan Metode Multi Attribute Utility Theory ( Maut )," vol. 7, no. 2, 2019, [Online]. Available: https://ejournal.stmikgici.ac.id/.

[2] D. Aldo and Ardi, "Sains dan Teknologi Informasi Sistem Pakar Diagnosa Penyakit Limfoma dengan Metode Certainty Factor," vol. 5, no. 1, 2019.

[3] D. Aldo and D. Riliyanda, "Aplikasi Sistem Pakar Dalam Mendiagnosa Penyakit Infertilitas Pada Pria," vol. 7, no. 1, pp. 2031, 2019.

[4] D. Aldo and S. E. Putra, "Sistem Pakar Diagnosis Hama dan Penyakit Bawang Merah Menggunakan Metode Dempster 
Shafer Expert System for Diagnosis Pests and Shallots Diseases Using Dempster Shafer Method," vol. 9, no. 28, 2020, doi: 10.34010/komputika.v9i2.2884.

[5] D. Aldo, “identifikasi jumlah produksi produk dengan metode fuzzy tsukamoto berbasiS WEB," JURSIMA, vol. 7, no. 1, pp. 49-59, 2019.

[6] D. A. Alwendi, "Sistem Pendukung Keputusan Pemilihan Toko Handphone Terbaik Di Kota Padangsidimpuan Menggunakan Metode Oreste," JURSIMA J. Sist. Inf. dan Manaj., vol. 8, no. 1, 2020.

[7] S. A. Faiz, A. D. Wicaksono, and D. Dinanti, "Model SupplyDemand Lahan Pertanian Dengan Konsep Ecological Footprint ( Studi Kasus: Desa-desa yang Berbatasan dengan Kota Malang )," vol. 9, pp. 29-38, 2017.

[8] F. Avani, A. G. Tamrin, and T. L. A. Sucipto, "Analisis Supply And Demand Tenaga Kerja Bidang Bangunan Kabupaten," vol. 5, no. 1, 2019.

[9] S. R. Angga Saputra Dwi Wardhana, Suhariyanto, "Analisa Supply Dan Demand Beton Readymix," vol. 9, no. 1, 2015.

[10] R. F. Schiozer, "Determinants of Supply and Demand for Trade Credit by Micro , Small and Medium-Sized Enterprises," no. iii, pp. 208-222, 2015, doi: 10.1590/1808-057x201500940.

[11] M. Miharja, R. Planning, $H$.
Pradhitasari, U. Infrastructure, and M. Dwiputri, "Supply And Demand Carrying Capacity In Developing Park And Ride Scheme In East Corridor Of Bandung City ( Cileunyi District And Its Surrounding )," no. 2007, pp. 22-24, 2014.

[12] Y. Sugiarti, "Perancangan Sistem Informasi Agribisnis ECommerce Buah Pisang," vol. 8, no. 1, pp. 71-82, 2014.

[13] Atikah, "Analisa Dan Perancangan Sistem Informasi Pengadaan Bahan Baku Pada PT. XYZ," vol. 1, no. 2, pp. 109-119, 2016.

[14] E. W. Fridayanthie, "Perancangan Sistem Informasi Permintaan Barang ATK Berbasis Web Pada Badan Pendapatan Daerah Kota Tangerang," vol. XX, no. 1, pp. 26-30, 2018.

[15] I. Aoliya, E. N. Siahaan, P. Studi, $\mathrm{S}$. Informasiuniversitasraharja, $\mathrm{P}$. Barang, and B. Obyek, "Rancangan Sistem Informasi Pengadaan Barang Pada Koperasi Karyawan Aqua Group Dengan Metodologi Berorientasi Obyek," pp. 111-120.

[16] R. S. Pressman, Software Engineering A Practitioner's Approach, Eighth Ed. McGrawHill. 2015.

[17] H. Al Fatta, Analisis dan Perancangan Sistem Informasi untuk Keunggulan Bersaing Perusahaan dan Organisasi Modern. 2007. 